\title{
РАЗРАБОТКА АЛГОРИТМА УПРАВЛЕНИЯ РАЗВИТИЕМ СЕКТОРА МАЛОГО И СРЕДНЕГО ПРЕДПРИНИМАТЕЛЬСТВА В РОССИИ
}

\author{
(c) 2021 Ял-Яваш Сергей Вячеславович \\ соискатель Высшей инженерно-экономической школы, ИПМЭиТ \\ Санкт-Петербургский политехнический университета Петра Великого, Россия, Санкт-Петербург \\ E-mail: yalymovser@mail.ru \\ (c) 2021 Зайцев Андрей Александрович \\ профессор Высшей инженерно-экономической школы, ИПМЭиТ \\ Санкт-Петербургский политехнический университета Петра Великого, Россия, Санкт-Петербург \\ E-mail: andrey_z7@mail.ru
}

Особенности развития сектора МСП указывают на несовершенство существующей системы государственной поддержки, требующей обновления аналитических инструментов для принятия управленческих решений. Поэтому в статье разработан алгоритм управления развитием сектора малого и среднего предпринимательства через синтез модели оценки влияния макроинституциональной среды на элементы микроинституциональной среды субъекта МСП и модели проталлакса элементов микроинституциональной среды субъекта МСП. Это позволяет аналитику получить необходимый и достаточный информационный массив, на основе которого определяются характеристики и специфика реализации опциона на налоговые обязательства субъекта МСП и опциона на финансовую устойчивость МСП.

Ключевые слова: сектор малого и среднего предпринимательства, инструменты государственной поддержки, опцион на налоговые обязательства, опциона на финансовую устойчивость

Средняя рентабельность субъектов МСП составляет 5,76\% [1], что нельзя назвать высоким результатом. Характерными причинами в данном случае являются низкая покупательная способность населения, совокупное высокое налоговое бремя (в частности, высокий уровень НДС) и недостаточный уровень государственной поддержки. Так как субъекты МСП работают зачастую напрямую с физическими лицами, уровень благосостояния населения напрямую влияет на финансовые результаты субъектов МСП. Следствием данного факта являются дополнительные сложности для субъектов МСП не только в долгосрочном, но и среднесрочном планировании. Это ведёт к высокой чувствительности к большинству неблагоприятных явлений внешней экономической среды. Субъекты МСП вынуждены существовать за счет малой операционной прибыли, зачастую не имеют накоплений и средств для инвестирования в собственное развитие, что значительно повышает волатильность данного сектора экономики.

Описанная специфика развития сектора МСП указывает на несовершенство существующей системы государственной поддержки, а также общую поляризацию экономики с явным уклонов в сторону развития крупного бизнеса. Таким образом, принадлежность предприятия к сектору МСП во много может указывать на значительные риски планирования, следствием чего в условиях макроэкономической нестабильности и ресурсных ограничений может быть общеотраслевая нестабильность.

В рамках государственной политики применяются различные инструменты по поддержке развития малого и среднего предпринимательства. Одно из важных мест занимает льготное налогообложение, которое реализуется в рамках стимулирующей функции налогов. Это позволяет отдельным налогоплательщикам уплачивать налоги в меньшем объёме [2], что даёт возможность уменьшить денежные оттоки предприятия, а также формирует более благоприятные условия для ведения бизнеса.

Для развития и совершенствования поддержки предприятий малого и среднего предпринимательства в России, стоит обратить внимание на опыт других стран. Работа «Инвестиции и финансирование МСП с учетом взаимодействия банковской и налоговой систем, а так же за счет развития партнерства государственного и частного секторов экономики», авторами которой 
выступили исследователи из Китая - Пенгфей Луо, Дандан Сонг, Биао Чен, посвящена изучению возможностей развития малого и среднего предпринимательства за счет государственных субсидий и взаимодействия банковской и налоговой систем в Китае [3].

Так, в работе авторы уделили внимание развитию партнерских отношений между бизнесом и государством в КНР. Предложили инвестиционные стратегии и рассчитали размер предполагаемых потерь при выстраивании партнерских отношений с государственными органами власти. По мнению авторов исследования использование взаимозависимости банковской и налоговой систем экономики, представляет собой так называемый инструмент развития МСП, который может смягчить проблему недостаточного инвестирования средств в условиях рыночной нестабильности. Кроме того, была выявлена зависимость структуры кредитования МСП от размера налоговой ставки, распределения инвестиционных затрат, кредитного мультипликатора и волатильности. Данная работа показала всю сложность развития МСП в условиях постоянно меняющихся факторов внешней среды. Колебание даже одного из них приводит не только к прямым изменениям, но и к изменениям реакции субъектов МСП на изменение иных факторов.

В работе [4] рассматривается взаимосвязь между инновациями на уровне фирм и внешним финансированием МСП. Для проведения исследования была использована выборка из 13430 фирм из стран Восточной Европы и Центральной Азии. По мнению авторов, исследование имеет несколько важных политических последствий. Во-первых, важно иметь более широкую формализованную финансовую систему, которая способна заботиться о предпринимателях и различных стадиях жизненного цикла малых компаний.

В статье [5] рассмотрена проблема ограниченности доступа МСП к финансированию. Поэтому меры по содействию доступу МСП к финансовым ресурсам, а также содействие формированию условий их более эффективного расходования являются неотъемлемой частью стратегии развития многих правительств. В работе [6] исследована общая развитость МСП в России с точки зрения устойчивости экономической среды в зависимости от экономических циклов.

При этом ключевой задачей процесса управления развитием сектора МСП является его син- хронизация с решениями, направленными на управление развитием крупного бизнеса в частности, и всей экономики России в целом. Как было показано в проведённых исследованиях $[7,8]$, процесс анализа для принятия управленческих решений относительно развития сектора МСП может быть представлен в виде следующих последовательных этапов:

1. Определение состояния макроинституциональной среды. На данном этапе производится поиск и агрегирование ключевых показателей-трансмиттеров макроинституциональной среды МСП.

2. Идентификация вектора и силы влияния макроинституциональной среды на субъекты микроинституциональной среды. На данном этапе производится расчет показателей-медиаторов микроинституциональной среды МСП.

3. Расчет показателей, характеризующих изменение вектора развития субъектов МСП и иных субъектов микроинституциональной среды МСП.

4. Определение параметров инструментов управления развитием сектора МСП.

Более подробно все эти этапы с учетом математического инструментария представлены на рисунке 1. Расшифровка переменных рисунка 1 представлена в таблице 1.

Рассмотрим реализацию указанного алгоритма на конкретном примере организации МСП в сфере общественного питания. В качестве конкурентов данного сектора может выступать доставка готовой еды и продуктов на дом, а также офлайн сектор по продаже продуктов питания. С учетом специфики пандемии, данный сектор испытывает значительное отрицательное воздействие со стороны макроинституциональной среды. По результатам идентификации и агрегирования информации, а также применения предложенного нечетко-множественного инструментария, были получены результаты, представленные на рис. 2.

Как видно на рисунке 2, макроинституциональная среда крайне негативно влияет на сектор общественно питая. Данный факт во многом связан с фактом окончания режима самоизоляции в этот период, следствием которого стала трансформация паттернов потребления, а также начинающийся период ресурсных ограничений. Для целей определения влияния информационной среды на сектор МСП в предыдущем периоде, использовались данные новостных агентств 


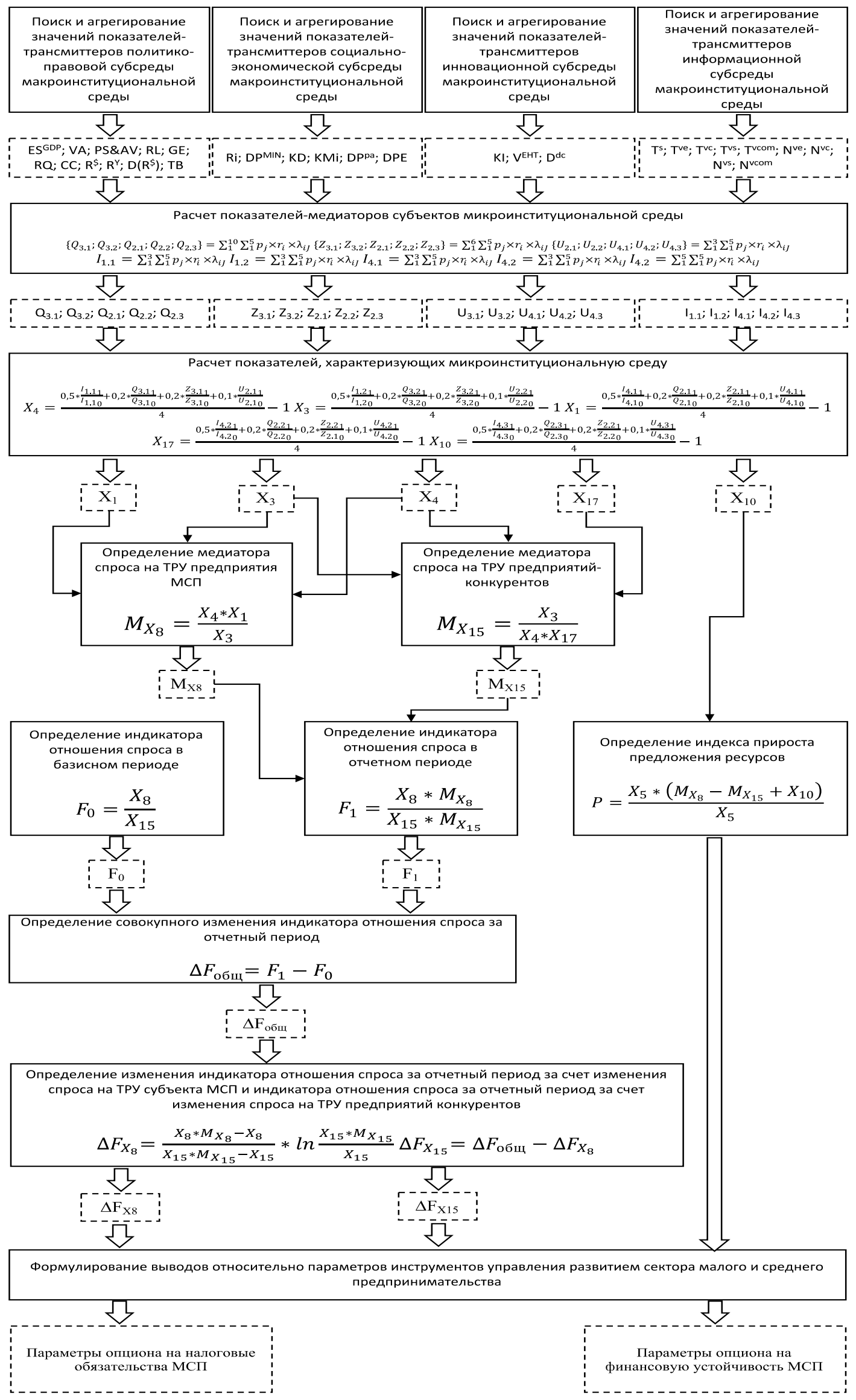


Таблица 1. Пояснение к переменным алгоритма управления развитием сектора малого и среднего предпринимательство (составлено автором на основе [8])

\begin{tabular}{|c|c|}
\hline Показатель & Расшифровка \\
\hline$\Delta \mathrm{F}_{\mathrm{X} 15}$ & $\begin{array}{l}\text { изменение индикатора отношения спроса за отчетный период за счет изменения спроса на } \\
\text { ТРУ предприятий конкурентов }\end{array}$ \\
\hline$\Delta \mathrm{F}_{\mathrm{X} 8}$ & $\begin{array}{l}\text { изменение индикатора отношения спроса за отчетный период за счет изменения спроса на } \\
\text { ТРУ субъекта МСП }\end{array}$ \\
\hline$\Delta \mathrm{F}_{\mathrm{O}} щ$ & совокупное изменение индикатора отношения спроса за отчетный период. \\
\hline CC & контроль коррупции (Control of Corruption). \\
\hline $\mathrm{D}(\mathrm{R} \$)$ & годовая дисперсия курса рубля по отношению к доллару. \\
\hline Ddc & доля внутренних затрат на исследования и разработки, в процентах к ВВП. \\
\hline DPMIN & доля населения с денежными доходами ниже величины прожиточного минимума. \\
\hline DPpa & прирос доли населения пенсионного возраста. \\
\hline DPE & доля людей с высшим образованием. \\
\hline ESGDP & отношение объема экспортируемых ТРУ к ВВП страны. \\
\hline $\mathrm{F}_{0}$ & индикатор отношения спроса в базисном периоде. \\
\hline $\mathrm{F}_{1}$ & индикатор отношения спроса в отчетном периоде. \\
\hline GE & $\begin{array}{l}\text { процесс формирования политических решений и стратегий, стабильность заявленного по- } \\
\text { литического курса, уровень компетентности государственных служащих и их политическая } \\
\text { независимость, качество предоставления общественных услуг, а также способность эффек- } \\
\text { тивно управлять государственными ресурсами (Government Effectiveness). }\end{array}$ \\
\hline $\mathrm{I}_{1.1}$ & $\begin{array}{l}\text { интегральный показатель влияния информационной среды на изменение конкурентоспо- } \\
\text { собности ТРУ субъекта МСП. }\end{array}$ \\
\hline $\mathrm{I}_{1.2}$ & $\begin{array}{l}\text { интегральный показатель влияния информационной среды на изменение конкурентоспо- } \\
\text { собности ТРУ предприятий-конкурентов субъекта МСП. }\end{array}$ \\
\hline $\mathrm{I}_{4.1}$ & $\begin{array}{l}\text { интегральный показатель влияния информационной среды на изменение конкурентоспо- } \\
\text { собности ТРУ субъекта МСП за счет влияния предприятий-комплименторов. }\end{array}$ \\
\hline $\mathrm{I}_{4.2}$ & $\begin{array}{l}\text { интегральный показатель влияния информационной среды на изменение конкуренто- } \\
\text { способности ТРУ предприятий-конкурентов субъекта МСП за счет влияния предприятий- } \\
\text { комплименторов }\end{array}$ \\
\hline $\mathrm{I}_{4.3}$ & $\begin{array}{l}\text { интегральный показатель влияния информационной среды на изменение воздействия ком- } \\
\text { плименторов на поставщиков ресурсов субъекта МСП. }\end{array}$ \\
\hline $\mathrm{j}$ & номер подмножеств базового терм множеств. \\
\hline KD & коэффициент Джини. \\
\hline KI & коэффициент изобретательской активности. \\
\hline KMi & коэффициент миграционного прироста. \\
\hline $\mathrm{MX} 15$ & медиатор спроса на ТРУ предприятий-конкурентов. \\
\hline MX8 & медиатор спроса на ТРУ предприятия МСП. \\
\hline Nvcom & коэффициент целевого содержания информационной среды комплименторов субъекта МСП. \\
\hline Nve & коэффициент целевого содержания информационной среды субъекта МСП. \\
\hline NVS & коэффициент целевого содержания информационной среды поставщиков субъекта МСП. \\
\hline $\mathrm{Nvc}$ & коэффициент целевого содержания информационной среды конкурентов субъекта МСП. \\
\hline $\mathrm{P}$ & индекс прироста предложения ресурсов. \\
\hline pj & узловые точки 01-носителя. \\
\hline PS\&AV & $\begin{array}{l}\text { политическая стабильность и отсутствие политического насилия, преступности и терро- } \\
\text { ризма, мирная передача власти конституционным путем (Political Stability and Absence of } \\
\text { Violence). }\end{array}$ \\
\hline $\mathrm{Q}_{2.1}$ & $\begin{array}{l}\text { интегральный показатель влияния политико-правовой среды на изменение конкурентоспо- } \\
\text { собности ТРУ субъекта МСП за счет влияния предприятий-комплименторов. }\end{array}$ \\
\hline $\mathrm{Q}_{2.2}$ & $\begin{array}{l}\text { интегральный показатель влияния политико-правовой среды на изменение конкуренто- } \\
\text { способности ТРУ предприятий-конкурентов субъекта МСП за счет влияния предприятий- } \\
\text { комплименторов. }\end{array}$ \\
\hline $\mathrm{Q}_{2.3}$ & $\begin{array}{l}\text { интегральный показатель влияния политико-правовой среды на изменение воздействия } \\
\text { комплименторов на поставщиков ресурсов субъекта МСП. }\end{array}$ \\
\hline
\end{tabular}




\begin{tabular}{|c|c|}
\hline$Q_{3.1}$ & $\begin{array}{l}\text { интегральный показатель влияния политико-правовой среды на изменение конкурентоспо- } \\
\text { собности ТРУ субъекта МСП. }\end{array}$ \\
\hline$Q_{3.2}$ & $\begin{array}{l}\text { интегральный показатель влияния политико-правовой среды на изменение конкурентоспо- } \\
\text { собности ТРУ предприятий-конкурентов субъекта МСП. }\end{array}$ \\
\hline $\mathrm{R}^{\$}$ & курс рубля по отношению к американскому доллару. \\
\hline $\mathrm{Ri}$ & реальные располагаемые денежные доходы населения. \\
\hline$r_{j}$ & удельный вес показателя. \\
\hline RL & $\begin{array}{l}\text { наличие в государстве справедливого, исполнимого и доступного свода норм, регламенти- } \\
\text { рующих базовые социальные и экономические потребности и активности населения (Rule of } \\
\text { Law). }\end{array}$ \\
\hline RQ & $\begin{array}{l}\text { отсутствие бремени административного регулирования, а также способность государствен- } \\
\text { ных органов формулировать и реализовывать рациональную политику и генерировать } \\
\text { правовые акты, которые способствуют развитию экономики (Regulatory Quality). }\end{array}$ \\
\hline $\mathrm{RY}$ & курс рубля по отношению к китайскому юаню. \\
\hline TB & усредненный уровень налогового бремени \\
\hline $\mathrm{TS}$ & общая тональность информационной среды \\
\hline Tvcom & направленная тональность информационной среды комплименторов субъекта МСП \\
\hline Tve & направленная тональность информационной среды субъекта МСП \\
\hline TVS & направленная тональность информационной среды поставщиков субъекта МСП \\
\hline TVc & направленная тональность информационной среды конкурентов субъекта МСП \\
\hline $\mathrm{U}_{2.1}$ & $\begin{array}{l}\text { интегральный показатель влияния инновационной среды на изменение конкурентоспособ- } \\
\text { ности ТРУ субъекта МСП }\end{array}$ \\
\hline $\mathrm{U}_{2.2}$ & $\begin{array}{l}\text { интегральный показатель влияния инновационной среды на изменение конкурентоспособ- } \\
\text { ности ТРУ предприятий-конкурентов субъекта МСП }\end{array}$ \\
\hline $\mathrm{U}_{4.1}$ & $\begin{array}{l}\text { интегральный показатель влияния инновационной среды на изменение конкурентоспособ- } \\
\text { ности ТРУ субъекта МСП за счет влияния предприятий-комплименторов. }\end{array}$ \\
\hline $\mathrm{U}_{4.2}$ & $\begin{array}{l}\text { интегральный показатель влияния инновационной среды на изменение конкурентоспо- } \\
\text { собности ТРУ предприятий-конкурентов субъекта МСП за счет влияния предприятий- } \\
\text { комплименторов. }\end{array}$ \\
\hline $\mathrm{U}_{4.3}$ & $\begin{array}{l}\text { интегральный показатель влияния инновационной среды на изменение воздействия ком- } \\
\text { плименторов на поставщиков ресурсов субъекта МСП }\end{array}$ \\
\hline VA & $\begin{array}{l}\text { готовность государственных органов управления к подотчетности посредствам механиз- } \\
\text { мов обратной связи с представителями гражданского общества, развитые демократические } \\
\text { институты и независимую СМИ (Voice and Accountability). }\end{array}$ \\
\hline VEHT & экспорт российских высокотехнологичных товаров \\
\hline $\mathrm{X}_{1}$ & $\begin{array}{l}\text { индекс изменения конкурентоспособности ТРУ субъекта МСП за счет влияния предприятий- } \\
\text { комплименторов }\end{array}$ \\
\hline $\mathrm{X}_{3}$ & индекс изменения конкурентоспособности ТРУ предприятий-конкурентов субъекта МСП \\
\hline $\mathrm{X}_{4}$ & индекс изменения конкурентоспособности ТРУ субъекта МСП \\
\hline $\mathrm{X}_{10}$ & индекс изменения воздействия комплименторов на поставщиков ресурсов субъекта МСП. \\
\hline $\mathrm{X}_{17}$ & $\begin{array}{l}\text { индекс изменения конкурентоспособности ТРУ предприятий-конкурентов субъекта МСП за } \\
\text { счет влияния предприятий-комплименторов }\end{array}$ \\
\hline $\mathrm{Z}_{2.1}$ & $\begin{array}{l}\text { интегральный показатель влияния социально-экономической среды на изменение конку- } \\
\text { рентоспособности ТРУ субъекта МСП за счет влияния предприятий-комплименторов. }\end{array}$ \\
\hline $\mathrm{Z}_{2.2}$ & $\begin{array}{l}\text { интегральный показатель влияния социально-экономической среды на изменение кон- } \\
\text { курентоспособности ТРУ предприятий-конкурентов субъекта МСП за счет влияния } \\
\text { предприятий-комплименторов }\end{array}$ \\
\hline $\mathrm{Z}_{2.3}$ & $\begin{array}{l}\text { интегральный показатель влияния социально-экономической среды на изменение воздей- } \\
\text { ствия комплименторов на поставщиков ресурсов субъекта МСП }\end{array}$ \\
\hline $\mathrm{Z}_{3.1}$ & $\begin{array}{l}\text { интегральный показатель влияния социально-экономической среды на изменение конку- } \\
\text { рентоспособности ТРУ субъекта МСП. }\end{array}$ \\
\hline $\mathrm{Z}_{3.2}$ & $\begin{array}{l}\text { интегральный показатель влияния социально-экономической среды на изменение конку- } \\
\text { рентоспособности ТРУ предприятий-конкурентов субъекта МСП }\end{array}$ \\
\hline$\lambda \mathrm{ij}$ & критерий распознания частных показателей со значениями 01-носителя \\
\hline
\end{tabular}




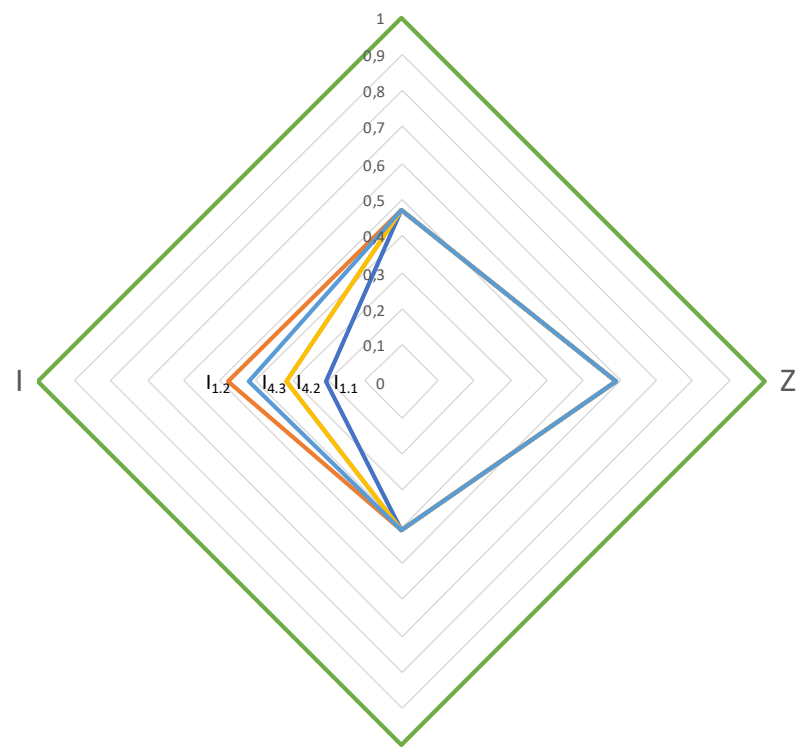

Рисунок 2. Состояние макроинституциональной среды сектора общественного питания Санкт-Петербурга по состоянию на июнь 2020 г.

(в частности сайта газеты «Московский комсомолец» и иных сайтов) и групп в социальной сети «ВКонтакте» за период январь - февраль 2020 года. Результаты оценки влияния со стороны макроинституциональной среды на анализируемый сектор в советующем периоде представлены на рисунке 3.

Как можно видеть на приведенной диаграмме, влияние со стороны макроинституциональной среды на соответствующий сектор диаметрально противоположное в равнении с альтернативными данными за текущий период. Данный факт безусловно связан со спецификой пандемии. По результатам оценки были определены показатели-медиаторы микроинституциональной среды МСП: $\mathrm{X}_{1}=0,18 ; \mathrm{X}_{3}=0,21 ; \mathrm{X}_{4}=0,16$; $\mathrm{X}_{10}=0,2 ; \mathrm{X}_{17}=0,18$. Значения показателей медиаторов значительно ниже единицы, что указывает на кране отрицательное воздействие.

На основе полученных данных может быть проанализирован проталлакс элементов микроинституциональной среды МСП. Предположим,

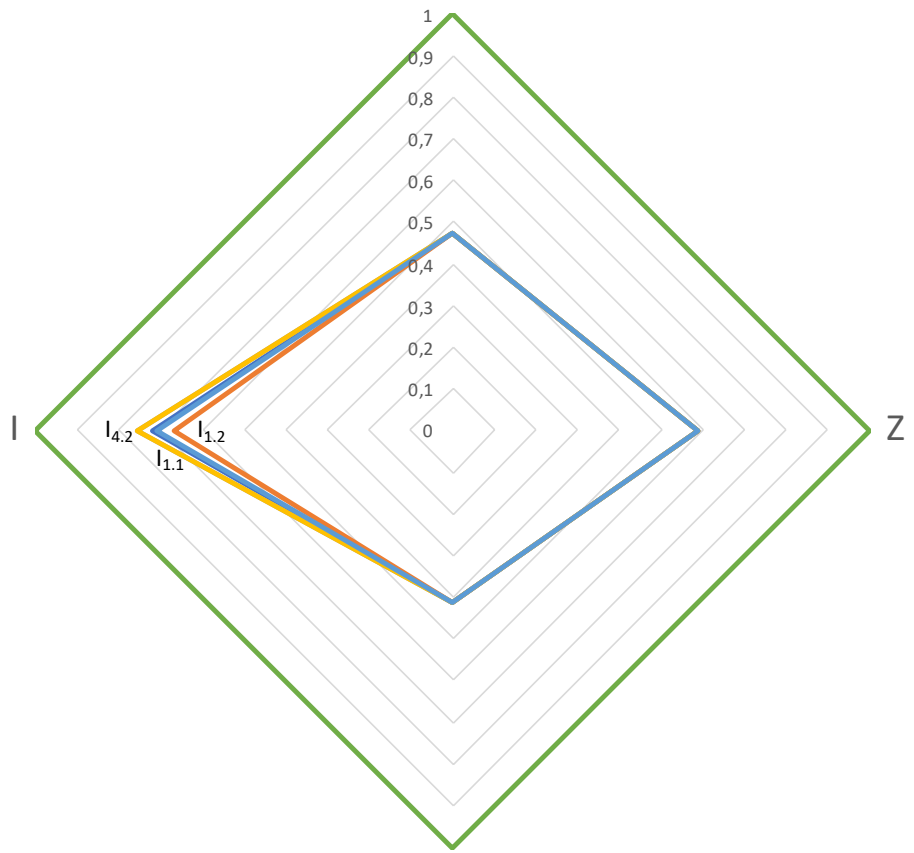

U

Рисунок 3. Состояние макроинституциональной среды сектора общественного питания Санкт-Петербурга по состоянию на январь-февраль 2020 года 
что потенциальный спрос на ТРУ субъектов МСП, а также потенциальный спрос на ТРУ конкурентов субъектов МСП со стороны потребителей равны друг другу и составляют условную единицу. В соответствии с данным допущением, получаемые результаты моделирования также представлены в условных единицах. На рисунке 4 представлена эволюционная визуализация результатов анализа проталлакса элементов микроинституциональной среды МСП, в соответствии с исследуемым сектором.

В соответствии с полученными результатами можно заключить, что совокупное изменение индикатора отношения спроса за отчетный период составила 0,982 условные единицы, или 98,2\%. Данное изменение на 71\% обеспечено изменением спроса на ТРУ предприятий конкурентов и на $27 \%$ изменением спроса на ТРУ субъекта МСП. Таким образом, помимо значительно влияния пандемии непосредственно на сектор общественного питания, также необходимо отметить дополнительно воздействие со стороны конкурентных сил. Т.е., представленные инструменты управления развитием МСП должны не только компенсировать воздействие со стороны макроинституциональной среды, но и повысить конкурентные преимущества соответствующего сектора МСП.

Реализации соответствующих стратегий будут способствовать следующие предложения сектору МСП: опционные контракты на налоговые обязательства в соответствии с пессимистическим прогнозом выручки; опционные контракты на финансовую устойчивость МСП, при одновременной выдаче кредитных средств в размере до 40\% от базы опционного контракта. При этом в обоих случаях необходимо ограничить реализацию данного инструмента для выделенных конкурентов соответствующего сектора МСП.

Таким образом, полученный алгоритм развивает инструменты в сфере информационной аналитики и принятия управленческих решений [9]. Является универсальным, масштабируемым и эффективным в реализации, так как позволяет наглядно увидеть общую картину состояния анализируемого сектора МСП, детально ее проанализировать и сформулировать конкретные решения по управлению его развитием.

\section{Библиографический список}

1. Малое и среднее предпринимательство в России.- Текст: электронный // Федеральная служба государственной статистики: [сайт]. - URL: https://gks.ru/folder/210/document/13223 (дата обращения: 03.04.2021).

2. Кучеренко, О. В. Особенности налогового регулирования малого и среднего предпринимательства в России и за рубежом // Наука о человеке: гуманитарные исследования. - 2015. - C. 184-193.

3. Luo Pengfei, Song Dandan, Chen Biao Investment and financing for SMEs with bank-tax interaction and publicprivate partnerships // International Review of Economics \& Finance, 2020, vol. 65, issue C, 163-172

4. Nirosha Hewa Wellalagea, Viviana Fernandez Innovation and SME finance: Evidence from developing countries // International Review of Financial Analysis. 2019. https://doi.org/10.1016/j.irfa.2019.06.009

5. Renate Kersten, Job Harms, Kellie Liket, Karen Maas Small Firms, large Impact? A systematic review of the SME Finance Literature // World Development, 2017, vol. 97, issue C, 330-348

6. Жолболдуева Д.Ш., Аширалиева Б. А. Малый и средний бизнес в развитых странах // Известия вузов Кыргызстана, № 6, 2015

7. Родионов Д. Г., Ялымов С. В., Сергеев Д. А. Фискальный инструмент управления развитием сектора малого и среднего предпринимательства //Экономические науки. - 2020. - № . 189. - С. 92-98

8. Родионов Д. Г., Ялымов С. В., Конников Е. А. Модель институциональной среды субъектов малого и среднего предпринимательства //Экономические науки. - 2020. - № . 190.- С. 138-146.

9. Стецюнич Ю.Н., Зайцев А.А. Информационные технологии в сфере налогообложения // Цифровая трансформация экономики и промышленности. Сборник трудов научно-практической конференции с зарубежным участием, 2019. С. 646-655. 